\section{PERFIL E FORMAÇÃO DO PROFISSIONAL EM BIBLIOTECAS ESCOLARES NO BRASIL, ESPANHA E PORTUGAL'}

\author{
Mariângela Spotti Lopes Fujita* \\ Maria Del Carmen Agustín-Lacruz \\ Ana Lúcia Terra ${ }^{* * *}$
}

RESUMO Este trabalho tem como objetivo principal conhecer, de modo detalhado, o perfil profissional dos bibliotecários escolares do Brasil, Espanha e Portugal. Nesse sentido, foram definidos três objetivos específicos: a) conhecer o marco legal que rege o seu desempenho profissional, nesses países, b) identificar e descrever as funções e tarefas executadas pelo responsável pela biblioteca da escola, incluindo seu tempo de dedicação e c) conhecer a formação inicial e contínua específica dos bibliotecários escolares. Para o efeito, procedeu-se a uma análise de literatura e de legislação relevantes, além da recolha de dados sobre uma amostra de bibliotecários dos três países, através de um inquérito por questionário. Entre os principais objetivos alcançados, destaca-se a caracterização detalhada dos perfis profissionais dos responsáveis por bibliotecas escolares, no Brasil, Espanha e Portugal, identificando o seu trabalho e as suas funções, o tipo de formação educacional que possuem, o nível alcançado, as áreas e matérias de que se ocupam em seu desempenho profissional, a educação formal e continuada que possuem e o número de horas dedicadas à biblioteca da escola.

Palavras-chave: Bibliotecário escolar. Formação profissional. Perfil profissional.

\footnotetext{
* Doutora em Ciências da Comunicação pela Universidade de São Paulo, Brasil. Docente permanente no Programa de Pós-Graduação em Ciência da Informação da Universidade Estadual Paulista Julio de Mesquita Filho, Brasil.

E-mail: fujita@marilia.unesp.br.

** Doutora em Filosofía e Letras pela Universidad de Zaragoza, Espanha. Professora Titular da Universidad de Zaragoza, Espanha.

E-mail: cagustin@unizar.es.

**** Doutora em Ciências Documentais pela Universidade de Coimbra, Portugal. Professora do Instituto Politécnico do Porto, Portugal.

E-mail: anaterra@iscap.ipp.pt.
}

\section{INTRODUÇÃO}

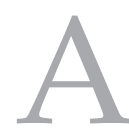
biblioteca escolar é um centro de recursos bibliográficos e documentais para a aprendizagem, cujo propósito é atender às necessidades indicadas por professores e estudantes, no projeto do centro educacional (FUENTES ROMERO, 2006, 23 e GRUPO DE TRABAJO, 2013, 44). Os profissionais que ali trabalham devem ser especialistas em promoção da leitura, em estratégias que facilitem a autonomia no acesso e uso da informação, assim como peritos em proporcionar informação para facilitar as tarefas docentes (MUÑOZ-VELEZ,

I Artigo revisto e ampliado a partir de trabalho apresentado no III Congresso ISKO Espanha-Portugal/XIII Congresso ISKO Espanha, 2017.
2010, 48). A especificidade das habilidades do bibliotecário escolar motivou diferentes instituições internacionais do mais alto nível e responsabilidade, no âmbito educacional e bibliotecário, como é o caso da UNESCO e IFLA, que estabeleceram, há décadas, recomendações sobre os perfis profissionais das pessoas responsáveis por bibliotecas escolares. Entretanto, essas indicações carecem de valor legal e têm distintos graus de cumprimento, nos diferentes países. A questão não é inútil, porque a qualidade dos sistemas bibliotecários está na base do aprimoramento dos respectivos sistemas educacionais.

Este trabalho se propõe, como objetivo principal, conhecer o perfil profissional dos bibliotecários do Brasil, Espanha e Portugal. Esse objetivo geral é atingido por três objetivos 
específicos: a) conhecer o marco legal que rege o seu desempenho profissional, nesses países; b) identificar e descrever as funções e tarefas executadas pelo responsável pela biblioteca da escola, incluindo seu tempo de dedicação; e c) conhecer a formação requerida aos bibliotecários escolares, seus tipos e características.

Em geral, a bibliografia específica sobre os perfis profissionais do bibliotecário escolar não é abundante e se encontra dispersa, em distintos tipos de obra sobre esses centros. Não obstante, é possível rastrear, na bibliografia, até três orientações diferentes: em primeiro lugar, os trabalhos de Giménez Chornet (2014), Muñoz-Vélez (2010), Camacho Espinosa (2004) Baró, Mañá e Vellosillo (2001) e, especialmente, o Grupo de Trabalho sobre Perfis Profissionais, pertencente ao Conselho de Cooperação Bibliotecária do Ministério de Educação, Cultura e Desporte da Espanha (2013, 44), mostram clara preferência pela figura de um "responsável da biblioteca escolar". Em segundo lugar, especialistas, como Rueda (2015), Varela Prado (2013), Lage Fernández (2013), Durban Roca et al. (2013), Becerra (2012), García Guerrero (2010, 2012), Durban Roca, Cid Prolongo e García Guerrero (2012), García Guerrero y Luque Jaime (2011) y Durban Roca (2010) são favoráveis a que exista um perfil para o professor da escola ou professor com formação específica sobre bibliotecas. E, finalmente, alguns autores, como Garcez e Cunha (2011, 2015), Garcez (2014), Jiménez-Fernández e Cremades-García (2014), Soto Alfaro (2007) e Cuozzo e Ladrón de Guevara e Verde (2007), são partidários de uma dupla qualificação, tanto em Biblioteconomia como em Educação ou Pedagogia, assim como preconizam que esse profissional dispor de um leque de qualificações mais amplo e interdisciplinar.

Nesse contexto, a situação compartilha características comuns e, ao mesmo tempo, demonstra peculiaridades, nos três sistemas estudados.

\section{PERFIL DOS PROFISSIONAIS DE BIBLIOTECAS ESCOLARES NO BRASIL, ESPANHA E PORTUGAL: Marco Legal}

No Brasil, há uma clara contradição entre o que idealmente se espera da biblioteca escolar, como espaço profissional ocupado por bibliotecário, e o que a realidade mostra ser o mais exequível. Embora a Lei $n^{\circ} 12.224$, de 24 de maio de 2010 (BRASIL, 2010), a qual dispõe sobre a universalização das bibliotecas, nas instituições de ensino do país, estabeleça que seja respeitada a profissão do bibliotecário, em seu Artigo $3^{\circ}$, a realidade revelada pelos estudos diagnósticos realizados é de que poucos bibliotecários com formação em Biblioteconomia ocupam cargos específicos no magistério.

A função de bibliotecário no quadro de pessoal das Secretarias Municipais ou Estaduais de Educação e das escolas de Educação Básica ainda é de difícil implantação, evidenciando que pouco se avançou com relação ao que determina a Lei $\mathrm{n}^{\mathrm{o}}$ 12.224, de 24 de maio de 2010. A existência da função de bibliotecário, no quadro de pessoal das escolas, é uma necessidade para a ocupação desse mercado de trabalho pelo profissional. Porém, há iniciativas sendo implementadas, a partir de políticas públicas em âmbito estadual e municipal, como é o caso relatado por Garcez (2014).

Por outro lado, existem casos em que outros profissionais desenvolvem atividades na biblioteca e, na maioria, são funcionários da própria escola, em readaptação. Sobre isso, Silva e Ventorim (2016) remetem a resultados de pesquisa que investigou a atuação do trabalhador docente na função de bibliotecário escolar, em sete Estados do Brasil, nos anos de 2009-2010. Tais resultados revelam que, no caso do Estado de Espírito Santo, onde se apresentou o menor quantitativo de professores (1481), foram identificados 12 bibliotecários. Os autores, diante desses dados, analisam que a função do bibliotecário, nas escolas de Educação Básica, ainda não exige formação específica, contrariando o artigo $3^{\circ}$ da Lei Federal 12.244, de 2010, e que professores afastados das salas de aula, por problemas de saúde ou outros motivos, assumem a função, sem ter formação específica ou capacitação para a gestão da biblioteca escolar.

O fato é que a própria existência de bibliotecas escolares é menor em relação à quantidade de escolas públicas e privadas encontradas no país, conforme dados oficiais fornecidos pelo censo escolar de 2016, efetuado pelo INEP (2017): “O país conta com 186,1 mil escolas de educação básica, [...] 50.5\% das escolas de educação básica possuem biblioteca e/ou sala de leitura (esse percentual é de $53,7 \%$ para as que ofertam ensino fundamental e de $88,3 \%$ no ensino médio)." 
A literatura da área não contempla muitos estudos sobre perfil e formação profissional de bibliotecários escolares, no Brasil (CAMPELLO, 2015). Constata-se, não obstante, por mera dedução quantitativa, que a formação inicial de bibliotecários no país, é realizada em 42 cursos de graduação em 22 Estados e Distrito Federal (LISTA, 2018), insuficiente para a demanda do total de milhares de unidades de ensino de Educação Básica. Embora os conteúdos não privilegiem tipos específicos de bibliotecas, a tendência do mercado de trabalho está mais inclinada à oferta de postos de trabalho em bibliotecas universitárias e especializadas. $\mathrm{Ob}$ viamente, se houvesse a oferta de vagas em bibliotecas escolares, com certeza teríamos reflexos positivos, quer em estrutura e conteúdo curriculares da formação inicial em Biblioteconomia, quer em pesquisas no tema de biblioteca escolar, mais postos de trabalho etc. Portanto, o ponto fundamental de tudo isso é a criação e a ocupação da função de bibliotecário, ou por profissionais com formação específica em Biblioteconomia ou por educadores capacitados e supervisionados em unidades de ensino da Educação Básica.

A configuração da realidade atual do bibliotecário escolar, no Brasil, leva a pensar que o problema é de caráter estrutural, seja pelo aspecto administrativo para existência da função, seja pela necessidade organizativa e de gestão, pois a lei existe, porém, a execução estrutural para sua implementação depende da iniciativa dos governantes e dos gestores da Educação Básica, à semelhança do praticado no Estado de Santa Catarina, que formou a rede com coordenação central e a criação de cargos de bibliotecários na estrutura de pessoal.

$\mathrm{Na}$ Espanha, o sistema educacional considera que as bibliotecas escolares são serviços essenciais para os alunos, de acordo com a Lei Orgânica de Educação (LOE) (ESPAÑA, 2006), a qual, em seu artigo 113.1, estabelece a obrigatoriedade de que todas as escolas disponham de uma biblioteca escolar. No entanto, essa norma não determina que tipo de profissional deve cuidar dela. Carece-se, portanto, de uma legislação de caráter nacional que regule, de forma especifica, essa figura. $\mathrm{Na}$ Espanha, cada região fixa suas próprias regras, dentro do funcionamento e organização geral das escolas.

Em Portugal, em 1997, começou a ser implementado o Programa da Rede de Bibliotecas Escolares, contudo, só em 2009 foi oficialmente definido um procedimento específico de seleção de recursos humanos, com a criação da função de professor bibliotecário (PORTUGAL, 2009). Ficou assim estabelecido que as bibliotecas escolares deveriam ser geridas por docentes com formação adequada para o exercício de funções bibliotecárias. Para o efeito, anualmente, o Gabinete da Rede de Bibliotecas Escolares publica uma lista de cursos (doutoramento, mestrado, licenciatura, pós-graduações e especializações) considerados adequados para a formação de competências próprias do bibliotecário escolar.-

O documento de 2009 (PORTUGAL, 2009), atualizado em 2015 (PORTUGAL, 2015), não fazendo uma descrição específica das competências do professor bibliotecário, define grandes áreas de atuação, constituindo a principal referência para o exercício dessas funções.

Assim, primeiramente, indica-se que ao professor bibliotecário compete assegurar o serviço de biblioteca para os alunos. Aqui, importa sublinhar a orientação da biblioteca para os seus principais utilizadores - os alunos -, ainda que seja sua obrigação atender a toda a comunidade escolar. Além disso, o professor bibliotecário deverá trabalhar como um pivô, favorecendo a articulação das atividades da biblioteca com os objetivos do projeto educativo. Nesse sentido, tanto a biblioteca como o professor bibliotecário se afirmam como componentes transversais e estruturantes da estratégia global da escola. Ao professor bibliotecário cabe ainda as tarefas de gestão dos recursos humanos afetos à biblioteca, assumindo funções de organização operacional, para o bom funcionamento desse serviço de informação.

As funções seguintes incidem especificamente em áreas de índole técnica próprias dos serviços bibliotecários. De fato, caberá ao professor bibliotecário garantir a organização do espaço e assegurar a gestão funcional e pedagógica dos recursos materiais afetos à biblioteca, além de definir e operacionalizar uma política de gestão dos recursos de informação. Assim, será responsabilidade do professor bibliotecário a disposição física do espaço de trabalho e de conservação dos documentos, além de estruturar várias zonas, dentro da biblioteca, como espaços de acolhimento, espaços de leitura ou espaços de acesso e uso das TIC, entre outros. A gestão funcional e pedagógica dos recursos poderá incluir a definição de políticas de empréstimo, a seleção de recursos de informação adequados às atividades letivas e ex- 
tracurriculares ou a escolha do horário de abertura mais conveniente. A avaliação dos circuitos dos documentos, a escolha de regras de criação de metadados, no nível da descrição física e intelectual, ou o controlo da acessibilidade dos recursos informacionais poderão ser considerados dentro das funções inerentes à política de gestão dos recursos de informação.

Adicionalmente, é fixado que cabe ao professor bibliotecário apoiar as atividades curriculares e favorecer o desenvolvimento dos hábitos e práticas de leitura e das literacias da informação (competências da informação) e das mídias, em colaboração com toda a comunidade escolar. Nesse sentido, a função do professor bibliotecário afigura-se como instrumental e transversal, na medida em que não se circunscreve ao espaço da biblioteca e ao uso dos seus recursos, mas se alarga ao desenvolvimento de competências no sentido amplo de literacia da informação e das mídias, bem como de práticas de leitura. Apoiar atividades livres, extracurriculares e de enriquecimento curricular, incluídas no projeto educativo da instituição onde a biblioteca se insere, constitui outra função do professor bibliotecário. Nessa perspectiva, o trabalho do professor bibliotecário também extravasa o espaço circunscrito da biblioteca. O mesmo acontece, quando se indica que lhe compete estabelecer redes de trabalho cooperativo, desenvolvendo projetos de parceria com entidades locais, não se limitando ao contexto da escola, porém, almejando o contexto local circundante.

Por fim, fica estabelecido que o professor tem a incumbência de implementar, anualmente, os procedimentos de avaliação dos serviços, definidos pelo Gabinete Coordenador da Rede de Bibliotecas Escolares (GCRBE), em articulação com os órgãos de direção da instituição de ensino onde se enquadra a biblioteca. Dessa forma, promove-se o envolvimento do professor bibliotecário num processo de avaliação contínua dos serviços bibliotecários, o qual sustenta uma dinâmica de autoavaliação cíclica do funcionamento das unidades que integram a Rede de Bibliotecas Escolares. Por fim, cabe ao professor bibliotecário representar a biblioteca escolar, conforme o que for definido em regulamento próprio. Em Portugal, a Rede de Bibliotecas Escolares encontrou nos professores de carreira, com formação complementar na área da biblioteconomia, um elemento estruturante da afirmação da biblioteca escolar junto da sua comu- nidade. Não tendo seguido nenhum referencial profissional de tipificação das suas competências, foram definidas, por via legal, as grandes áreas da sua atuação.

\section{METODOLOGIA}

A metodologia usada combinou a recolha de dados bibliográficos e legislativos sobre as bibliotecas escolares do Brasil, Espanha e Portugal, em específico no que respeita aos profissionais que exercem funções nesse tipo de serviços de informação, com a realização de um estudo empírico para recolher dados sobre os perfis dos colaboradores das bibliotecas escolares. Assim, numa primeira fase, procedeu-se à análise de bibliografia específica sobre o perfil profissional dos bibliotecários escolares, incluindo monografias, artigos de revistas e comunicações em conferências, de modo a captar as diferentes linhas de reflexão sobre a temática, criando um substrato teórico consentâneo com a nossa abordagem empírica. Essa abordagem foi complementada com o levantamento e a análise de documentos legislativos e outros regulamentos aplicáveis às bibliotecas escolares dos três países estudados, de sorte a se verificarem semelhanças e aspetos distintivos, em termos de orientações políticas e opções teórico-práticas, no que concerne à definição do perfil dos profissionais atuando em bibliotecas escolares. Adicionalmente, esse conhecimento do contexto legal, onde se concretiza o exercício do profissional das bibliotecas escolares, apresenta-se como um contributo relevante para situar contextualmente o estudo empírico desenvolvido numa terceira etapa.

Com efeito, concretizou-se um estudo empírico para observar e conhecer o desempenho profissional dos responsáveis das bibliotecas escolares. Foi elaborado um questionário, o qual foi aplicado a uma amostra de cada um dos países envolvidos neste estudo.

O questionário inclui 13 perguntas e foi difundido online, através do envio de convites para participar da pesquisa, em listas de discussão relacionadas com bibliotecas escolares dos três países, bem como para contactos pessoais de bibliotecários escolares, no período de 20 de fevereiro a 22 de junho de 2017. Adicionalmente, foi pedido aos respondentes que divulgassem o questionário junto de outros professores bibliotecários, aplicando-se 
a técnica do snowball sampling. Considerando essa forma de divulgação do questionário nos três países, não é possível estimar o número potencial de respondentes. Por outro lado, dado que não existem estatísticas públicas sobre o número professores bibliotecários, embora esteja disponível o número de bibliotecas escolares existentes em Portugal, também não se pode inferir a representatividade da amostra, face ao universo total de professores bibliotecários, nos três países. Ainda assim, considera-se que os dados recolhidos ilustram a realidade específica dos participantes do inquérito, podendo fornecer pistas interessantes para estudos futuros.

Foram recolhidos 37 questionários, no Brasil, 45, na Espanha, e 46, em Portugal. Apesar do período alargado para recolha de dados e do envio de convites para participar em períodos diferentes, o número de questionários recolhidos não foi muito elevado. Na perspectiva das autoras, essa falta de adesão ao questionário pode decorrer, em parte, da saturação dos potenciais inquiridos pela solicitação muito frequente para responder a inquéritos online.

Esse questionário destinava-se a abordar, de modo comparativo, a formação e o perfil profissional dos bibliotecários escolares dos países envolvidos no estudo, pelo que as perguntas estavam orientadas para recolher dados sobre essas matérias. A estrutura-base do questionário foi a mesma nos três países, havendo apenas ajustes pontuais em algumas questões, de maneira a adequá-las a cada contexto nacional. Assim, no Google forms, foi necessário criar três questionários diferentes, cada qual associado a um coletor. Note-se ainda que, na Espanha, o questionário estava em espanhol, enquanto, no Brasil e em Portugal, foi usado o português, com adaptações pontuais.

A primeira pergunta destinava-se a saber se os inquiridos desempenhavam funções, no âmbito de uma biblioteca escolar. Em caso negativo, o questionário terminava aqui. Se a resposta fosse positiva, seguiam-se mais 12 perguntas. A segunda questão pretendia identificar os níveis de ensino abrangidos pela biblioteca escolar, tendo havido as necessárias adaptações a cada um dos países envolvidos. A terceira pergunta destinava-se a averiguar o papel que o respondente desempenhava, na biblioteca escolar (responsável, colaborador ou técnico).

Essa pergunta era complementada pela quarta, na qual era necessário identificar o perfil profissional (professor, bibliotecário, professorbibliotecário, técnico-operacional ou outro). As perguntas seguintes destinavam-se a conhecer a formação acadêmica e o exercício profissional dos inquiridos, no âmbito das bibliotecas escolares. Por sua vez, a quinta pergunta pedia que fosse indicado o nível de formação acadêmica detida no âmbito das bibliotecas/bibliotecas escolares (licenciatura, mestrado, doutoramento ou cursos de especialização).

A questão seguinte aprofundava essa matéria, solicitando a indicação das áreas de formação acadêmica específica frequentadas, no âmbito das bibliotecas escolares, incluindo-se as opções: formação básica em biblioteconomia (ordenar, organizar e fazer empréstimos), formação avançada em biblioteconomia (catalogar, indexar, classificar e conceber projetos), formação para a promoção da leitura, formação de utilizadores/ literacia informacional, formação no âmbito das Tecnologias de Informação e Comunicação, outras áreas ou nunca frequentou formação acadêmica específica para as bibliotecas escolares. A pergunta seguinte destinava-se a saber se tinham frequentado formação contínua, no contexto das bibliotecas/bibliotecas escolares.

Em caso de resposta positiva, a oitava questão complementava esta, pedindo que fossem nomeadas as áreas de formação frequentadas, a saber: formação básica em biblioteconomia (ordenar, organizar e fazer empréstimos), formação avançada em biblioteconomia (catalogar, indexar, classificar e conceber projetos), formação para a promoção da leitura, formação de utilizadores/literacia informacional, formação no âmbito das Tecnologias de Informação e Comunicação ou outras áreas.

Em seguida, na nona pergunta, solicitava-se a identificação das modalidades da formação contínua frequentada, havendo, como opções, cursos e jornadas escolhidas pela instituição ou realizadas por iniciativa pessoal, formação autodidata, participação em grupos de trabalho ou outras modalidades. Já a pergunta 10 incidia sobre as áreas de atividade desempenhadas no âmbito das bibliotecas escolares, havendo as seguintes opções: atendimento de utilizadores, pesquisa de informação, empréstimos, organização do acervo documental, catalogação, indexação e classificação do acervo documental, seleção e aquisição dos recursos informacionais, formação de utilizadores, atividades de dinamização 
(exposição, concursos etc.), concepção e redação de documentos de gestão da biblioteca (planificações, relatório, projeto, avaliações), atividades de apoio letivo, atividades extracurriculares e outras. A pergunta seguinte destinava-se a saber o número de horas semanais dedicadas ao trabalho da biblioteca escolar.

Por fim, as duas últimas questões incidiam sobre a experiência letiva, solicitando a indicação da área de lecionação (pergunta 12) e o número de anos no ensino (pergunta 13).

No que respeita ao tratamento de dados, importa referir que as respostas relativas a cada país foram registradas no coletor associado ao respetivo questionário no Google forms. Na sequência, os resultados foram codificados, de modo a serem tratados quantitativamente, aplicando técnicas de estatística descritiva, para uma posterior análise comparativa dos dados mais relevantes de cada país.

É essa análise comparativa da formação e do perfil profissional dos bibliotecários escolares dos países envolvidos no estudo, resultante dos dados do estudo empírico, que se apresenta no ponto seguinte.

\section{RESULTADOS}

Os resultados do estudo comparado sobre perfil e formação profissional do bibliotecário escolar, no Brasil, Espanha e Portugal, foram obtidos da coleta de dados com questionário, cujas análises estão organizadas a partir de duas categorias, com a comparação entre os três países: Perfil profissional e Formação Profissional.

\section{I Perfil profissional dos responsáveis pelas bibliotecas}

Abrange os aspectos: funções; áreas de atividades executadas; e tempo de dedicação; níveis de ensino das escolas com biblioteca escolar.

\section{Perfil profissional autodeclarado (Questões I, 3 e 4):}

Em Portugal e Brasil, todos os inquiridos revelaram desempenhar funções no âmbito de uma biblioteca escolar. Na Espanha, 83,3\% dos entrevistados trabalham ou colaboram com a biblioteca da escola, mas $16,7 \%$ dos inquiridos não tinham nenhuma conexão com a biblioteca, pelo que a sua participação no questionário terminou nessa pergunta.
Afirmam serem os responsáveis pela biblioteca escolar $87 \%$ dos inquiridos portugueses, enquanto há $13 \%$ colaboradores. Dos inquiridos brasileiros, 91,9\% dos respondentes indica ser o responsável pela biblioteca e 8,1\%, colaborador. Na Espanha, $64,5 \%$ dos entrevistados são responsáveis e 35,5\% são colaboradores na biblioteca escolar (Tabela 1).

Tabela 1: Papel desempenhado na biblioteca escolar

\begin{tabular}{l|c|c|c}
\hline & $\begin{array}{c}\text { Brasil } \\
\text { (n.37) }\end{array}$ & $\begin{array}{c}\text { Espanha } \\
\text { (n.31) }\end{array}$ & $\begin{array}{c}\text { Portugal } \\
\text { (n.46) }\end{array}$ \\
\hline $\begin{array}{l}\text { Responsável pela } \\
\text { biblioteca escolar }\end{array}$ & $91,9 \%$ & $64,5 \%$ & $87,0 \%$ \\
\hline $\begin{array}{l}\text { Colaborador da } \\
\text { biblioteca escolar }\end{array}$ & $8,1 \%$ & $35,5 \%$ & $13,0 \%$ \\
\hline
\end{tabular}

Fonte: elaborada pelo autor

Referente ao perfil profissional autodeclarado, 73,9\% dos inquiridos portugueses mostra ser professor-bibliotecário, 23,9\%, professor, e 2,2\%, bibliotecário. No Brasil, 94,6\% dos respondentes brasileiros afirmam ser bibliotecários, um respondeu ser professor e um professor bibliotecário. $\mathrm{Na}$ Espanha, 30,4\% dos entrevistados são professores, 17,4\% bibliotecários, $13 \%$ professores bibliotecários, $17,4 \%$ afirmam-se técnicos e a maioria (52,2\%), que tem outro perfil profissional (Tabela 2).

Tabela 2: Perfil profissional: tipos

\begin{tabular}{l|c|c|c}
\hline & $\begin{array}{c}\text { Brasil } \\
\text { (n.37) }\end{array}$ & $\begin{array}{c}\text { Espanha } \\
\text { (n.23) }\end{array}$ & $\begin{array}{c}\text { Portugal } \\
\text { (n.46) }\end{array}$ \\
\hline Bibliotecário & $94,6 \%$ & $17,4 \%$ & $2,2 \%$ \\
\hline $\begin{array}{l}\text { Prof e s s or } \\
\text { Bibliotecário }\end{array}$ & $2,7 \%$ & $13,0 \%$ & $73,9 \%$ \\
\hline Professor & $2,7 \%$ & $30,4 \%$ & $23,9 \%$ \\
\hline Técnico & & $17,4 \%$ & \\
\hline Outro & & $52,17 \%$ & \\
\hline
\end{tabular}

Fonte: elaborada pelo autor 10 e 13):

Áreas de atividades executadas (Questões

Quanto às áreas de atividade na biblioteca escolar, todos os inquiridos evidenciam um papel polivalente, atuando em diversas áreas, simultaneamente (Tabela 3). 
Tabela 3: Áreas de atividade no âmbito da biblioteca escolar

\begin{tabular}{l|c|c|c}
\hline & Brasil (n.37) & $\begin{array}{c}\text { Espanha } \\
\text { (n.45) }\end{array}$ & $\begin{array}{c}\text { Portugal } \\
\text { (n.46) }\end{array}$ \\
\hline Atendimento de utilizadores/usuários & $89,7 \%$ & $86,7 \%$ & $79,2 \%$ \\
\hline Pesquisa de informação & $79,5 \%$ & $68,9 \%$ & $77,1 \%$ \\
\hline Empréstimos & $87,2 \%$ & $68,9 \%$ & $85,4 \%$ \\
\hline Organização do acervo documental & $84,6 \%$ & $68,9 \%$ & $79,2 \%$ \\
\hline Catalogação, indexação e classificação do acervo documental & $87,2 \%$ & $28,9 \%$ & $58,3 \%$ \\
\hline Seleção e aquisição dos recursos informacionais & $76,9 \%$ & $42,2 \%$ & $72,9 \%$ \\
\hline Formação de utilizadores/usuários & $84,6 \%$ & $42,2 \%$ & $77,1 \%$ \\
\hline Atividades de dinamização (exposições, concursos etc) & $76,9 \%$ & $55,6 \%$ & $91,7 \%$ \\
\hline $\begin{array}{l}\text { Concebe e redige documentos de gestão da biblioteca } \\
\text { (planificações, relatórios, projetos, avaliações) }\end{array}$ & $76,9 \%$ & $20,0 \%$ & $70,8 \%$ \\
\hline Atividades de apoio letivo & $79,5 \%$ & $40,0 \%$ & $79,2 \%$ \\
\hline Atividades extracurriculares & $35,9 \%$ & $33,3 \%$ & $64,6 \%$ \\
\hline Outras & $12,8 \%$ & $13,3 \%$ & $4,2 \%$ \\
\hline
\end{tabular}

Fonte: elaborada pelo autor

Em Portugal, a escolha mais frequente $(91,7 \%)$ diz respeito à concretização de atividades de dinamização (exposições, concursos etc.). No contexto brasileiro, essa opção atinge os $76,9 \%$ e, na Espanha, 55,6\%. No Brasil, o atendimento de usuários $(89,7 \%)$ é o mais comum, tal como na Espanha $(86,7 \%)$, porém, em Portugal, é menos representativo (79,2\%). Na Espanha, a segunda percentagem mais elevada $(68,9 \%)$ corresponde a três opções (pesquisa de informação, empréstimos e organização do acervo documental), as quais também apresentam números significativos, no Brasil $(79,5 \%$, pesquisa de informação; 87,2\%, empréstimos; e 84,2\%, organização do acervo) e, em Portugal (77,1\%, pesquisa de informação; empréstimos, 85,4\%; e $79,2 \%$, organização do acervo).
No contexto português, as tarefas biblioteconômicas de catalogação, indexação e classificação atingem os 58,3\%, enquanto as seleções e aquisições, 72,9\%. No Brasil, essas atividades apresentam um peso mais significativo, com $87,2 \%$ e $76,9 \%$, respectivamente. Ao contrário, na Espanha, são bem menos importantes, registrando-se $28,9 \%$, para a catalogação e indexação, e $42,2 \%$, para a seleção de recursos.

A formação de utilizadores/usuários atinge os 77,1\%, em Portugal, 84,6\%, no Brasil, e $42,2 \%$, na Espanha. A elaboração de documentos de gestão da biblioteca (relatórios, planificações, projetos) é bastante significativa, em Portugal $(70,8 \%)$ e no Brasil (76,9\%), mas pouco representativa, na Espanha (20\%). As atividades 
diretamente relacionadas com o ensino, como apoio letivo, são importantes em Portugal $(79,2 \%)$ e no Brasil $(79,5 \%)$, todavia, menos expressivas na Espanha (40\%). Já as atividades extracurriculares são pouco numerosas no Brasil $(35,9 \%)$ e na Espanha (33,3\%), contudo, mais relevantes em Portugal $(64,6 \%)$.

O tempo de experiência letiva (Questão 13) situa-se entre os 7 e os 39 anos, em Portugal, e, na Espanha, entre os 2 e os 16 anos. No Brasil, essa pergunta não foi atendida.

Evidencia-se atuação em diversas áreas e demonstra-se que os colaboradores da biblioteca escolar, nos três países, realizam atividades dedicadas a necessidades de seus usuários (atendimento ao usuário, pesquisa de informação, empréstimos, apoio letivo, literacia informacional, atividades extracurriculares); gestão documental (organização do acervo documental, tarefas biblioteconômicas de catalogação, indexação e classificação, seleção e aquisição de acervo documental) e gestão da biblioteca (planejamento, projetos e relatórios).

Os resultados apontam diferenças na indicação de atuação com relação às atividades de gestão documental, nas quais os profissionais brasileiros optaram por mais e os espanhóis e portugueses, por menos. Quanto às necessidades dos usuários, houve equilíbrio no quantitativo de respostas por parte de portugueses, espanhóis e brasileiros, embora existam menos ou mais indicações nas diferentes atividades de atendimento às necessidades dos usuários. Quanto às atividades de gestão da biblioteca escolar, são muito evidenciadas por profissionais brasileiros e portugueses e bem pouco por espanhóis.

\section{Tempo de dedicação (Questão I I):}

O número de horas semanais dedicadas à biblioteca varia, no Brasil, entre as $6 \mathrm{~h}$ e as $45 \mathrm{~h}$, na Espanha, entre as $2 \mathrm{~h}$ e as $35 \mathrm{~h}$, e em Portugal, entre os 45 minutos $\mathrm{e}$ as $45 \mathrm{~h}$. Verifica-se, portanto, alguma disparidade que reflete o facto de os colaboradores da biblioteca se dedicarem apenas à biblioteca ou não. Em termos de média, os inquiridos brasileiros dedicam $35,3 \mathrm{~h}$ semanais à biblioteca, os espanhóis, 7,4, e os portugueses, 22,5h. Aqui, há diferenças bem acentuadas entre os três países.
Com respeito ao tempo, os intervalos entre a quantidade de carga horária de dedicação são muito díspares, nos três países, com variações que vão de 45 minutos a 45 horas, e deixam a dúvida sobre os colaboradores da biblioteca se dedicarem apenas à biblioteca ou não. Portanto, a média semanal é, também, muito diferente entre os respondentes.

Níveis de ensino abrangidos pelas bibliotecas escolares "versus" atuação profissional

Figura 1: Níveis de ensino da BE - PT
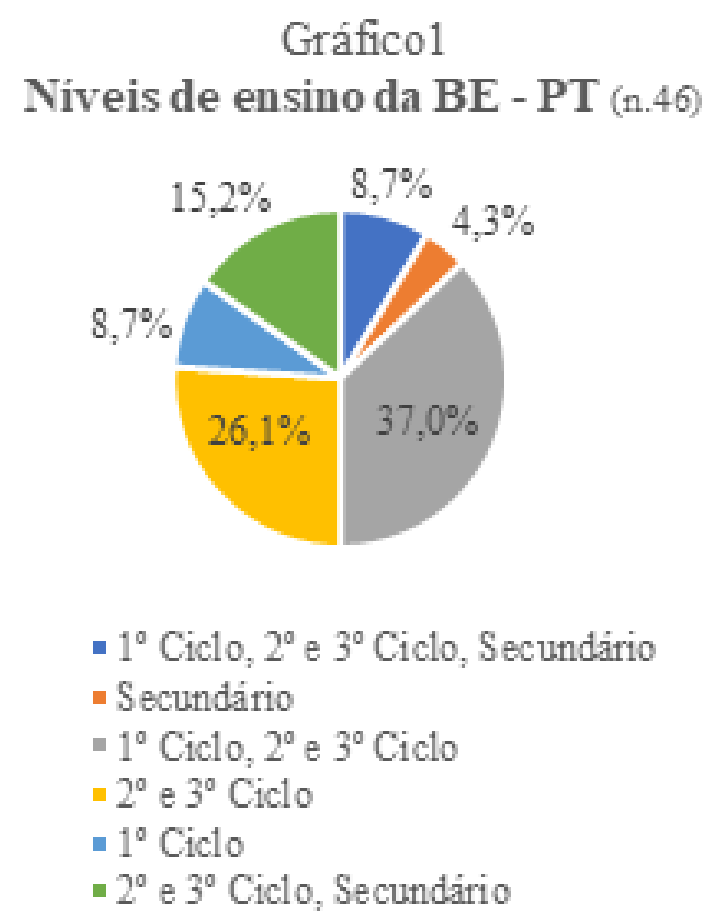

Fonte: elaborada pelo autor

Relativamente aos níveis de ensino abrangidos pela biblioteca escolar (Questão 2), em Portugal (Gráfico 1), constata-se que todos os níveis estão representados, predominando bibliotecas que englobam diversos graus de ensino. Assim, $37 \%$ incluem o $1^{\circ}, 2^{\circ}$ e $3^{\circ}$ ciclo, $26,1 \%$, o $2^{\circ}$ e $3^{\circ}$ ciclo, $15,2 \%$, o $2^{\circ}$ e o $3^{\circ}$ ciclo, bem como o secundário, havendo ainda 8,7\% que congregam todos os níveis de ensino. As bibliotecas dedicadas a um único ciclo de ensino são minoritárias: $8,7 \%$, no $1^{\circ}$ ciclo, e $4,3 \%$, no secundário. 
Figura 2: Níveis de ensino da BE - BR

\section{Gráfico 2}

Níveis de ensino da BE - BR (n.37)

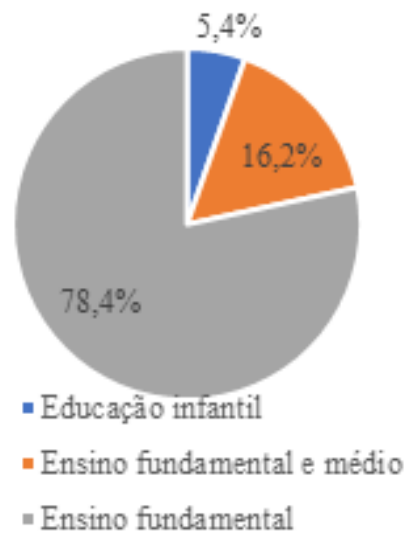

Fonte: elaborada pelo autor

No Brasil (Gráfico 2), a maioria das bibliotecas escolares dos inquiridos $(78,4 \%)$ abrange o ensino fundamental, $16,2 \%$, os dois níveis, fundamental e médio, e apenas $5,4 \%$, o ensino infantil.

Figura 3: Níveis de ensino da BE - ES

\section{Gráfico 3}

Níveis de ensino da BE - ES (n.31)

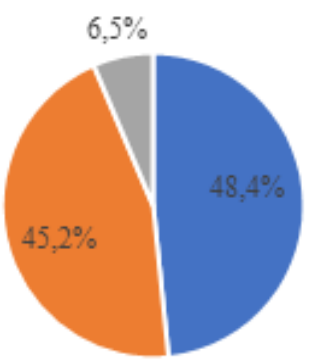

- Escola secundária - Escola primária " Escola de "bachillera to"

Fonte: elaborada pelo autor

$\mathrm{Na}$ Espanha (Gráfico 3), a maioria das escolas $(48,4 \%)$ corresponde a escolas secundárias, seguindo-se as bibliotecas de escolas primárias $(45,2 \%)$ e as escolas de "bachillerato" $(6,5 \%)$.

\subsection{Formação profissional dos responsáveis pelas bibliotecas}

Abarca os aspectos: nível de formação acadêmica; áreas de formação acadêmica inicial; áreas de formação acadêmica sobre biblioteca escolar; formação continuada; frequência de formação continuada.

\section{Nível de formação acadêmica (Questão 5)}

O nível de formação acadêmica, no âmbito das bibliotecas escolares, maioritário entre os respondentes portugueses, é o curso de especialização ou pós-graduação, registrando 60,9\% das escolhas (Tabela 4). Houve ainda 13\% a indicar que não tinha formação acadêmica, no âmbito das bibliotecas escolares. As restantes percentagens foram residuais, distribuindo-se da seguinte forma: 8,7\% têm formação no nível da licenciatura e um curso de especialização/ pós-graduação; 6,5\% têm mestrado e curso de especialização/pós-graduação, enquanto a mesma percentagem tem licenciatura; 2,2\% indicam ter mestrado, e mesma percentagem, doutoramento. 
Tabela 4: Nível de formação acadêmica obtido no âmbito das bibliotecas escolares

\begin{tabular}{l|c|c|c}
\hline & Brasil (n.37) & Espanha (n.45) & Portugal (n.46) \\
\hline Curso de especialização/pós-graduação & $40,5 \%$ & $33,3 \%$ & $60,9 \%$ \\
\hline Mestrado & $10,8 \%$ & & $2,2 \%$ \\
\hline Mestrado, Curso de especialização/pós-graduação & & $2,2 \%$ & $6,5 \%$ \\
\hline $\begin{array}{l}\text { Licenciatura ou Bacharelato/Diplomatura ou Grado/ } \\
\text { Graduação }\end{array}$ & $43,2 \%$ & $15,6 \%$ & $6,5 \%$ \\
\hline $\begin{array}{l}\text { Doutoramento } \\
\text { Não tenho formação acadêmica no âmbito das bibliotecas } \\
\text { escolares }\end{array}$ & $2,7 \%$ & & $2,2 \%$ \\
\hline $\begin{array}{l}\text { Licenciatura, Curso de especialização/pós-graduação } \\
\text { Diplomatura em Biblioteconomia/Licenciatura em } \\
\text { Documentação/Curso de especialização/Doutoramento }\end{array}$ & & $28,9 \%$ & $13,0 \%$ \\
\hline \begin{tabular}{l} 
Outras combinações \\
\hline
\end{tabular} & & $6,7 \%$ & $8,7 \%$ \\
\hline
\end{tabular}

Fonte: elaborada pelo autor

No Brasil, predomina $(43,2 \%)$ a formação no nível da graduação (bacharelato ou licenciatura), seguindo-se os cursos de especialização $(40,5 \%)$. Além disso, 10,8\% indicam ter mestrado e $2,7 \%$, doutoramento, aplicando-se a mesma percentagem aos que afirmam não ter formação acadêmica, no âmbito das bibliotecas escolares.

No contexto espanhol, os cursos de especialização/pós-graduação destacam-se com 33,3\%, mas há $28,9 \%$ dos inquiridos que asseveram não ter formação acadêmica, nesse âmbito. As restantes percentagens são residuais e combinam várias opções, variando entre os 6,7\% (licenciatura na área da Biblioteconomia/ Documentação, doutoramento e pós-graduação) e os 2,2\% (licenciatura, mestrado e cursos de pósgraduação/especialização).

Portugal tem maioria de profissionais com formação pós-graduada em nível de especialização $(60,9 \%)$ e $13 \%$ sem formação acadêmica, no âmbito das bibliotecas escolares; em comparação, na Espanha, há menos profissionais com especialização (33,3\%) e 28,9\% não têm formação acadêmica, nesse âmbito; no Brasil, predomina a formação em nível de graduação $(43,2 \%)$, seguida de quase o mesmo percentual com cursos de especialização (40,5\%). Poucos, entre Portugal, Espanha e Brasil, têm mestrado ou doutorado. Em áreas de formação acadêmica frequentadas nos cursos de graduação e pós-graduação, no nível de especialização, mestrado e doutorado, a formação diretamente relacionada com bibliotecas escolares é evidenciada pela maioria dos respondentes, entretanto, existe uma variação de tipos de formação acadêmica entre os três países.

\section{Áreas de formação acadêmica inicial (Questão 12)}

Em Portugal, relativamente à área científica de formação de base, predominam as Línguas (Português e Inglês), a História e a Educação Visual e Tecnológica, havendo também inquiridos de Matemática, Física, Biologia e Educação Física, entre outros. No Brasil, essa pergunta não foi considerada e, na Espanha, as respostas recolhidas foram pouco conclusivas.

\section{Áreas de formação acadêmica sobre biblioteca escolar (Questão 6):}

Relativamente às áreas de formação acadêmica frequentadas e diretamente relacionadas com as bibliotecas escolares, apenas $12,5 \%$ dos respondentes portugueses respondeu nunca ter tido qualquer formação, nesse âmbito (Tabela 5). 
Tabela 5: Áreas de formação acadêmica no âmbito das bibliotecas escolares

\begin{tabular}{|c|c|c|c|}
\hline & Brasil (n.39) & Espanha (n.45) & $\begin{array}{c}\text { Portugal } \\
\text { (n.46) }\end{array}$ \\
\hline $\begin{array}{l}\text { Formação avançada em Biblioteconomia (catalogar, indexar, } \\
\text { classificar, concepção de projetos) }\end{array}$ & $76,9 \%$ & $15,6 \%$ & $56,3 \%$ \\
\hline $\begin{array}{l}\text { Formação básica em Biblioteconomia (ordenar, organizar e fazer } \\
\text { empréstimos) }\end{array}$ & $5,1 \%$ & $26,7 \%$ & $43,8 \%$ \\
\hline Formação para a promoção da leitura & $15,4 \%$ & $75,6 \%$ & $70,8 \%$ \\
\hline Formação de utilizadores / literacia informacional & $2,6 \%$ & $48,9 \%$ & $58,3 \%$ \\
\hline Formação no âmbito das Tecnologias de Informação e Comunicação & $0,0 \%$ & $66,7 \%$ & $70,8 \%$ \\
\hline $\begin{array}{l}\text { Nunca frequentei formação acadêmica específica no âmbito das } \\
\text { bibliotecas escolares }\end{array}$ & $0,0 \%$ & $15,6 \%$ & $12,5 \%$ \\
\hline Outros & $0,0 \%$ & $2,2 \%$ & $4,2 \%$ \\
\hline
\end{tabular}

Fonte: elaborada pelo autor

As áreas de formação mais comuns incluem a promoção da leitura e as Tecnologias de Informação e Comunicação, ambas com $70,8 \%$ de escolhas. A formação de utilizadores/literacia da informação apresenta uma percentagem de $58,3 \%$, ao passo que a formação avançada em Biblioteconomia (catalogar, indexar, classificar e concepção de projetos) envolve $56,3 \%$ dos respondentes. Já a formação básica em Biblioteconomia (ordenar, organizar e fazer empréstimos) foi selecionada por $43,8 \%$ dos respondentes portugueses. Houve ainda $4,2 \%$ que escolheram a opção "outras", indicando pós-graduação em bibliotecas escolares e gestão de bibliotecas escolares.

No contexto brasileiro, a área de formação mais comum é a avançada em Biblioteconomia $(76,9 \%)$, seguindo-se a promoção da leitura, mas com uma percentagem bem mais reduzida $(15,4 \%)$. A formação de competência informacional (literacia informacional) foi escolhida por $2,6 \%$ dos inquiridos brasileiros, enquanto a formação básica em Biblioteconomia registrou 5,1\%. Frise-se que nenhum desses respondentes escolheu a formação na área das Tecnologias de Informação e Comunicação.

Na Espanha, a formação para a promoção da leitura foi a opção mais escolhida $(75,6 \%)$, enquanto as Tecnologias de Informação e Comunicação foram a segunda opção com mais escolhas $(66,7 \%)$. A formação de utilizadores/ literacia da informação também foi referida por quase metade dos respondentes $(48,9 \%)$. A formação básica em Biblioteconomia (26\%) e a formação avançada na mesma área $(15,6 \%)$ apresentam números menos expressivos. Salienta-se ainda que $15,6 \%$ reconhecem não ter nenhuma formação acadêmica específica, na área das bibliotecas escolares.

Enquanto em Portugal e Espanha, as áreas de Promoção da leitura, Tecnologias de Informação e Comunicação (TIC) e Literacia da informação foram as mais indicadas, no Brasil, a maioria identificou a Formação avançada em Biblioteconomia (catalogar, indexar, classificar e concepção de projetos), poucos identificaram Promoção em leitura e nenhum, Tecnologias de Informação e Comunicação (TIC).

\section{Formação continuada em serviço (Questões 8 e 9):}

Em Portugal, predomina a formação para a promoção da leitura $(85,4 \%)$ e a formação relacionada com as Tecnologias de Informação e Comunicação (81,3\%). A formação de utilizadores/ literacia da informação foi a escolha de $66,7 \%$ dos respondentes. Por seu lado, a formação básica em Biblioteconomia $(31,3 \%)$ e a formação avançada $(37,5 \%)$ não parecem suscitar tanto interesse. Houve ainda $10,4 \%$ dos inquiridos a referir que não frequentaram formação continuada específica relativa às bibliotecas escolares (Tabela 6). 
Tabela 6: Áreas de formação continuada no âmbito das bibliotecas escolares

\begin{tabular}{l|c|c|c}
\hline & Brasil (n.36) & $\begin{array}{c}\text { Espanha } \\
\text { (n.45) }\end{array}$ & $\begin{array}{c}\text { Portugal } \\
\text { (n.46) }\end{array}$ \\
\hline $\begin{array}{l}\text { Formação avançada em Biblioteconomia (catalogar, indexar, } \\
\text { classificar, concepção de projetos) }\end{array}$ & $8,3 \%$ & $26,7 \%$ & $37,5 \%$ \\
\hline $\begin{array}{l}\text { Formação básica em Biblioteconomia (ordenar, organizar e } \\
\text { fazer empréstimos) }\end{array}$ & $5,6 \%$ & $31,1 \%$ & $31,3 \%$ \\
\hline Formação para a promoção da leitura & $69,4 \%$ & $60,0 \%$ & $85,4 \%$ \\
\hline Formação de utilizadores/Literacia informacional & $11,1 \%$ & $42,2 \%$ & $66,7 \%$ \\
\hline $\begin{array}{l}\text { Formação no âmbito das Tecnologias de Informação e } \\
\text { Comunicação }\end{array}$ & $2,8 \%$ & $53,3 \%$ & $81,3 \%$ \\
\hline $\begin{array}{l}\text { Nunca frequentei formação acadêmica específica no âmbito das } \\
\text { bibliotecas escolares }\end{array}$ & $0,0 \%$ & $31,1 \%$ & $10,4 \%$ \\
\hline \begin{tabular}{l} 
Outros \\
\hline
\end{tabular}
\end{tabular}

Fonte: elaborada pelo autor

No Brasil, a formação para a promoção da leitura representou a opção com mais escolhas $(69,4 \%)$. As restantes opções evidenciam percentagens bem menores, com $11,1 \%$ para a formação de competência informacional e 8,3\% para a formação avançada em Biblioteconomia. A área das Tecnologias de Informação e Comunicação $(2,8 \%)$ e a formação básica em Biblioteconomia $(5,6 \%)$ apresentam valores residuais.

No contexto espanhol, a formação para a promoção e animação da leitura destaca-se com $60 \%$ das escolhas, seguem-se as Tecnologias de Informação e Comunicação (53,3\%) e a formação de utilizadores/literacia da informação $(42,2 \%)$. A formação básica $(31,1 \%)$ e avançada $(26,7 \%)$ em Biblioteconomia registrou valores inferiores. Houve ainda 31,1\% dos respondentes a referir que não têm formação específica em bibliotecas escolares.

No que respeita ao modo como foi adquirida essa formação (Questão 9), em Portugal (81,3\%) e no Brasil (51,3\%), predominou a escolha de cursos e jornadas frequentadas por iniciativa pessoal (Tabela 7).
Tabela 7: Modo como adquiriu a formação continuada específica sobre as bibliotecas escolares

\begin{tabular}{l|r|r|r}
\hline & $\begin{array}{r}\text { Brasil } \\
\text { (n.37) }\end{array}$ & \multicolumn{1}{|c|}{$\begin{array}{c}\text { Espanha } \\
\text { (n.45) }\end{array}$} & \multicolumn{1}{c}{$\begin{array}{c}\text { Portugal } \\
\text { (n.46) }\end{array}$} \\
\hline $\begin{array}{l}\text { Cursosejornadas } \\
\text { indicadas pela } \\
\text { sua própria } \\
\text { instituição }\end{array}$ & $23,1 \%$ & $48,9 \%$ & $54,2 \%$ \\
\hline $\begin{array}{l}\text { Cursosejornadas } \\
\text { realizadas por } \\
\text { iniciativa pessoal }\end{array}$ & $51,3 \%$ & $42,2 \%$ & $81,3 \%$ \\
\hline $\begin{array}{l}\text { F o r m a ç ã o } \\
\text { autodidata }\end{array}$ & $17,9 \%$ & $28,9 \%$ & $33,3 \%$ \\
\hline $\begin{array}{l}\text { P a r t i i p çã o } \\
\text { em grupos de } \\
\text { trabalho }\end{array}$ & $7,7 \%$ & $44,4 \%$ & $39,6 \%$ \\
\hline
\end{tabular}

Fonte: elaborada pelo autor

Nesses dois países, a segunda escolha foi a frequência a cursos e jornadas indicados pela instituição onde os inquiridos trabalham, registrando-se $54,2 \%$, no contexto português, 
e 23,1\%, no brasileiro. A formação autodidata representa 17,9\%, no Brasil, e 33,3\%, em Portugal. A participação em grupos de trabalho atinge 39,6\%, em Portugal, e 7,7\%, no Brasil. Na Espanha, a formação específica continuada é alcançada mediante cursos realizados por iniciativa institucional $(48,9 \% \%)$ e iniciativa pessoal (42,2\%). Note-se que, aqui, a participação em grupos de trabalho $(44,4 \%)$ também apresenta uma percentagem significativa. Por seu lado, a formação autodidata registra $28,9 \%$ das escolhas.

A formação continuada é efetivada assiduamente pelos profissionais dos três países, mais como iniciativa pessoal, no Brasil e Portugal, e em partes iguais, pessoal e institucional, na Espanha, cujas áreas de formação predominantes são Promoção da leitura, nos três países, Tecnologias de Informação e Comunicação, em Portugal e Espanha, e Literacia da informação, também na Espanha e Portugal. Na Espanha, destacamse, ainda, a participação em grupos de trabalho e a formação autodidata. Por outro lado, indicações revelam profissionais, no Brasil, Espanha e Portugal, que nunca tiveram formação continuada específica sobre bibliotecas escolares.

\section{Frequência de formação continuada (Questão 7):}

No que toca à frequência de formação continuada, no âmbito das bibliotecas/ bibliotecas escolares, verifica-se que isso é uma realidade para a maioria dos inquiridos dos três países (Figura 4). Assim, em Portugal, há 97,8\% a declarar fazê-lo, no Brasil, são $67,6 \%$, e, na Espanha, 60\%.

Figura 4: Frequência de formação continuada no âmbito das BE

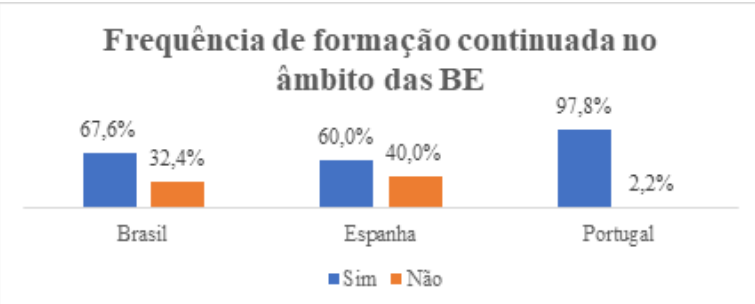

Fonte: elaborada pelo autor

\section{CONCLUSÕES}

O estudo comparado sobre perfil e formação profissional do bibliotecário escolar, no Brasil, Espanha e Portugal, foi realizado com análise da literatura sobre os marcos legais e exame dos resultados obtidos da pesquisa empírica, com aplicação de questionário, cuja amostra é de 128 respondentes, 37 do Brasil, 45 da Espanha e 46 de Portugal.

A análise de literatura conclui que os três países possuem marcos legais com diretrizes sobre a necessidade de existirem bibliotecas escolares em cada escola, porém, com diferenças sobre o perfil do profissional.

Assim, na Espanha, a norma não estabelece que tipo de profissional deve cuidar da biblioteca escolar e não existe regulamentação que especifique essa figura de profissional, circunstância agravada pelo fato de cada região da Espanha fixar suas próprias regras, dentro do funcionamento e organização geral das escolas.

No Brasil, ocorre a mesma situação da Espanha, no entanto, apesar de a legislação pertinente especificar a profissão do bibliotecário, não há regulamentação nos Estados e municípios para a ocupação da função de bibliotecário, no sistema nacional de ensino infantil, fundamental e médio.

Em Portugal, o Programa Rede de Bibliotecas Escolares existe desde 1997 e, em 2009, foi oficialmente definido um procedimento específico de seleção de recursos humanos, com a criação da função de professor bibliotecário, com competências definidas segundo o contexto da biblioteca escolar.

A análise das respostas aos questionários proporcionou resultados sobre o perfil profissional que, comparativamente, demonstram diferenças quanto à quantidade de autodeclarados responsáveis e colaboradores, entretanto, nos três países, é maior a quantidade de responsáveis, ao invés de colaboradores. Merece destaque ser maioria nas bibliotecas escolares portuguesas o professor bibliotecário, já que é função oficialmente criada desde 2009, em Portugal, o que revela um avanço dessa política pública. De modo contrário, na Espanha, não existe uma predominância do bibliotecário ou do professor bibliotecário, mas do professor assumindo a responsabilidade pela biblioteca escolar, reflexo da omissão da 
Lei Orgânica de Educação da Espanha, quanto à definição do tipo profissional e de falta de uma regulamentação geral. No Brasil, a maioria dos respondentes é bibliotecário e confirma a diretriz definida na Lei 12.224, de 2010, embora a amostra seja pequena e não haja dados para o cálculo de proporções.

Os resultados evidenciam que a figura do bibliotecário escolar é essencial para o bom funcionamento da biblioteca escolar. Ter um marco legal jurídico que regulamente o perfil profissional é quase tão determinante quanto ter pessoal qualificado, com suficiente disponibilidade de carga horária, para desenvolver as ações próprias da função. Ainda assim, é preciso avançar mais, no sentido de a biblioteca escolar fazer parte essencial da política pública de Educação desses países.

As atividades realizadas pelos respondentes são várias e, também, de rotinas de qualquer tipo de biblioteca, nas quais os inquiridos dos três países se dedicam em proporções equilibradas. Nas tarefas mais típicas de uma biblioteca escolar, tais como atividades extracurriculares, de apoio letivo, de dinamização (exposição, concursos etc.), pesquisa de informação e formação de utilizadores, destacam-se os respondentes de Portugal, na atividade de dinamização, do Brasil, na formação de utilizadores/usuários, e da Espanha, na pesquisa de informação.

Com relação à formação profissional, no âmbito das bibliotecas escolares, predomina entre os respondentes do Brasil o nível de graduação, seguido de cursos de especialização e uma minoria com curso de mestrado e doutorado; em Portugal, destaca-se uma maioria que tem curso de especialização acima da quantidade que tem graduação e, na Espanha, há menos profissionais com especialização. Essa diferença de nível de formação mostra a necessidade de oferecimento de cursos mais voltados aos temas de atuação na biblioteca escolar. Nesse sentido, observa-se que as áreas de formação acadêmica sobre biblioteca escolar dos cursos mais frequentados, no Brasil, são mais dedicadas às atividades de organização e representação da informação e concepção de projetos, enquanto em Portugal e Espanha, as áreas de formação mais indicadas são de promoção à leitura, literacia informacional e os de tecnologias de informação e comunicação. Todavia, na formação continuada, os respondentes do Brasil marcaram mais a promoção da leitura, assim como na Espanha e Portugal, acrescida das tecnologias de informação e comunicação.

O nível e as áreas de formação sobre bibliotecas escolares indicadas pelos respondentes demonstram diferenças entre os países que precisam ser realçadas, principalmente com relação ao Brasil, cuja ênfase se deu para atividades de rotinas de organização de bibliotecas e menos para atividades típicas de bibliotecas escolares, tais como promoção à leitura e competência/ literacia informacional. Faz-se necessária a investigação sobre o oferecimento de cursos e seus conteúdos, tendo em vista ser de interesse, no âmbito das bibliotecas escolares, maior envolvimento do responsável pelas áreas de formação de leitores e de competência informacional. No caso de Portugal e Espanha, a ênfase nas áreas de promoção da leitura, competência informacional e Tecnologias de informação e comunicação, e menos na formação básica em Biblioteconomia, apontam coerência com os resultados de a função de professor bibliotecário ser predominante, o que também sugere caminhos de investigação sobre a experiência de atuação e formação profissional, nesse contexto.

A relevância dos resultados obtidos, embora delimitados por uma amostra, confirma a necessidade de aproximação com a realidade das bibliotecas escolares e dos profissionais que ali trabalham. As experiências dos três países, cada um com sua realidade, têm avanços e fracassos que serão muito úteis aos pesquisadores, profissionais e gestores na condução dos problemas e soluções que certamente existem, quando se discute a situação das bibliotecas escolares, uma importante política pública na educação dos três países. Alertamos que estudos sobre perfil e formação profissional do responsável pela biblioteca escolar são necessários para a compreensão de suas dificuldades e obstáculos a serem superados, porém, há dificuldades sobre fontes de informações oficiais e profissionais a respeito, por exemplo, de quantas bibliotecas escolares têm bibliotecário ou professor responsável. Acompanhar o avanço ou o retrocesso dessa realidade é parte da solução do problema. 
Artigo recebido em I2/03/20I8 e aceito para publicação em 22/04/20।8

\section{PROFILE AND VOCATIONAL OF THE PROFESSIONAL IN SCHOOL LIBRARIES IN BRAZIL, SPAIN AND PORTUGAL}

ABSTRACT The main objective of this work is to know in detail the professional profile of school librarians in Brazil, Spain and Portugal. Three specific objectives were defined: a) to identify and describe the functions and tasks performed by these professionals; B) to determine the number of working hours devoted to school library management and c) to know school librarians initial and continuous training. For this purpose, an analysis of relevant literature and legislation was carried out in addition to data collection on a librarians' sample from the three countries, using a survey questionnaire. The main objectives achieved include the detailed characterization of the professional profiles of school librarians in Brazil, Spain and Portugal, identifying work and functions of schools librarians, the kind of education they have and the level attained. Areas and matters in which they are engaged in professional terms, the formal and continuous training they have, and the number of hours devoted to the school library are also presented.

Keywords: $\quad$ School libraries. Vocational training. Professional profile.

\section{REFERÊNCIAS}

BARÓ, M.; MAÑ́, T.; VELLOSILLO GONZÁLEZ, I. Bibliotecas escolares ¿para qué? Madrid: Anaya, 2001.

BECERRA, D. Maestro bibliotecario frente a bibliotecario escolar: reflexiones sobre el futuro de la biblioteca escolar. Mi Biblioteca, v.8, n.29. pp. 42-45, 2012. Disponível em: <http://www. alonsoquijano.org/mibiblioteca/contenido/ sites/default/ files/Bibliotecas \% 20Escolares $\% 20$ primavera\%202012.pdf> Acesso em: 09/01/2018.

BRASIL. Presidência da República. Lei $\mathbf{n}^{\mathbf{0}}$ 12.244 de 24 de maio de 2010- Dispõe sobre a universalização das bibliotecas nas instituições de ensino do país. Brasília, DOU de 25 de maio de 2010.

CAMACHO ESPINOSA, J. A. La biblioteca escolar en España: pasado, presente... y un modelo para el futuro. Madrid: Ediciones de la Torre, 2004.

CAMPELLO, B. S. Bibliotecas escolares e biblioteconomia escolar no Brasil. Biblioteca Escolar em Revista, v.4, n.1, pp. 1-25, 2015.
Disponível em: <http://www.revistas.usp. br/berev/article/view/106613>. Acesso em: $12 / 03 / 2018$

CUOZZO, G.; LADRÓN DE GUEVARA, M. C.; VERDE, M. La biblioteca escolar: usuarios y servicios. Buenos Aires: Alfagrama, 2007.

DURBAN ROCA, G.; CID PROLONGO, A.; GARCÍA GUERRERO, J. Programas para el desarrollo de la competencia informacional articulados desde la biblioteca escolar. Sevilla: Junta de Andalucía, Consejería de Educación, Dirección General de Evaluación y Ordenación Educativa, 2012. Disponível em:< http://www. juntadeandalucia.es/educacion/webportal/ abaco-portlet/content/9e344cda-a851-46bb-b6e107aced30d800>. Acesso em: 06/12/2017.

Nuevas dinámicas para la biblioteca escolar en la sociedad red: resituar sus acciones y acompañar la transformación en la escuela. Sevilla: Junta de Andalucía, Consejería de Educación, Dirección General de Evaluación y Ordenación Educativa, 2013. Disponível en:< http:/ / www.mecd.gob.es/cultura-mecd/ $\mathrm{dms} / \mathrm{mecd} /$ cultura-mecd/areas-cultura/libro/ $\mathrm{mc} /$ observatoriolect/redirige/ estudios-einformes/otros-informes-externos/bibliotecas/ 
nuevasdinamicas_bibliotecasescolares.pdf $>$. Acesso em: 19/11/2017.

La biblioteca escolar, hoy: un recurso estratégico para el centro. Barcelona: Graó, 2010.

ESPAÑA. Ley orgánica 2/2006, de 3 de mayo, de Educación.

FUENTES ROMERO, J. J. La biblioteca escolar. Madrid: Arco Libros, 2006.

GARCEZ, E. F. As competências do bibliotecário na educação básica: reflexões de rede. Perspectivas em Ciência da Informação, v.19, n. 4, pp. 13-24, 2014. Disponível en: http:// portaldeperiodicos.eci.ufmg.br/index.php/pci/ article/view/1923/1518 Acesso em: 28/02/2018.

GARCEZ, E. F., CUNHA, M. V. da. Las competencias del bibliotecario en una red de bibliotecas escolares para el estado de Santa Catarina, Brasil. In: Desafíos y oportunidades de las Ciencias de la Información y la Documentación en la era digital: actas del VII Encuentro Ibérico EDICIC 2015, Madrid, 16 y 17 de noviembre de 2015. Madrid: Universidad Complutense de Madrid, 2015. Disponível em:< http:/ / edicic2015.org.es/ucmdocs/actas/art12Fioravante_competencias-bibliotecario.pdf $>$. Acesso em: 28/02/2018.

GARCEZ, E. F.; CUNHA, M. V. da. O bibliotecário na escola de Educação Básica a partir de depoimentos de profissionais de Santa Catarina. Informação \& Sociedade: Estudos, v. 21, n. 2, p. 121-131, maio/ago. 2011. Disponível em: $\quad<$ http://www.ies.ufpb.br/ojs2/index. $\mathrm{php} /$ ies/article/view/9725/5985>. Acesso em: 20/02/2018.

GARCÍA GUERRERO, J. Utilidad de la biblioteca escolar: un recurso al servicio del proyecto educativo. Gijón: Trea, 2010.

Contribución de la biblioteca escolar al fomento de la lectura. Sevilla: Junta de Andalucía, Consejería de Educación, Dirección General de Evaluación y Ordenación Educativa, 2012. Disponível em: <http://www. juntadeandalucia.es/educacion/webportal/ abaco-portlet/content/9ca1d6f7-94e8-4f53-b3310be1a65803d9 >. Acesso em: 11/09/2018.

Organización y funcionamiento de la biblioteca escolar. Tareas básicas. Sevilla: Junta de Andalucía, Consejería de Educación, Dirección General de Evaluación y Ordenación Educativa, 2011. Disponível em: http://www. juntadeandalucia.es/educacion/webportal/ abaco-portlet/content/00d09468-926e-4bc9-9db5e8b7e70ffacb Acesso em: 28/02/2018.

GIMÉNEZ CHORNET, V. La biblioteca escolar: la lectura desde la adolescencia. Revista sobre la infancia y la adolescência, n.6, pp. 22-30, 2014. Disponível em: http://polipapers.upv.es/index. $\mathrm{php} / \mathrm{reinad} / \mathrm{article} / \mathrm{view} / 2186 /$ Acesso em: 26/02/2018.

GRUPO DE TRABAJO SOBRE PERFILES PROFESIONALES. Consejo de Cooperación Bibliotecaria. Perfiles profesionales del Sistema Bibliotecario Español: fichas de caracterización. Madrid: Secretaría General Técnica, 2013.

INSTITUTO NACIONAL DE ESTUDOS E PESQUISAS EDUCACIONAIS ANÍSIO TEIXEIRA - INEP. Censo escolar da educação básica 2016: notas estatísticas. Brasília: INEP, 2017;

JIMÉNEZ FERNÁNDEZ, C. M., CREMADESGARCÍA, R. Bibliotecas escolares: la necesaria transformación de un agente imprescindible. Barcelona: UOC, 2014.

LAGE FERNÁNDEZ, J. J. Bibliotecas escolares, lectura y educación. Madrid: Octaedro, 2013.

LISTA de escolas de biblioteconomia. In: WIKIPEDIA. Disponível em:< https:// pt.wikipedia.org/wiki/Lista_de_escolas_de_ biblioteconomia.>. Acesso em: 12/03/2018

MUÑOZ VÉLEZ, H. A. La formación profesional del bibliotecólogo: su aporte al desarrollo de la biblioteca escolar. Educación y Biblioteca, v.22, n.176, pp. 47-50, 2010. Disponível em: http://gredos.usal.es/jspui/ 
bitstream/10366/118861/1/EB14_N130_P31-37. pdf. Acesso em: 28/02/2018.

PORTUGAL. Portaria n. ${ }^{\circ} 756 / 2009$ de 14 de julho. 2009

Portaria n. ${ }^{\circ} 192-\mathrm{A} / 2015$ de 29 de junho.

2015

RUEDA, R. Bibliotecas escolares: guía para el profesorado de Educación Primaria. Madrid: Narcea, 2015.
SILVA, E. V.; VENTORIM, S. A condição docente do bibliotecário escolar na educação básica. Biblioteca Escolar em Revista, v.4, n.2, pp. 94108, 2016.

SOTO ALFARO, F. (coord.) La biblioteca escolar como espacio de aprendizaje. Madrid: Secretaría General Técnica, 2007.

VARELA PRADO, C. El maestro bibliotecario como agente propulsor de la biblioteca escolar. Revista Ibersid, v.7, pp. 103-116, 2013. Disponível em: http://www.ibersid.eu/ojs/ index.php/ibersid/article/view / 4086/3752 Acesso em: 01/03/2018. 


\section{APÊNDICE}

Quadro: Questionário sobre formação e perfil profissional dos bibliotecários escolares

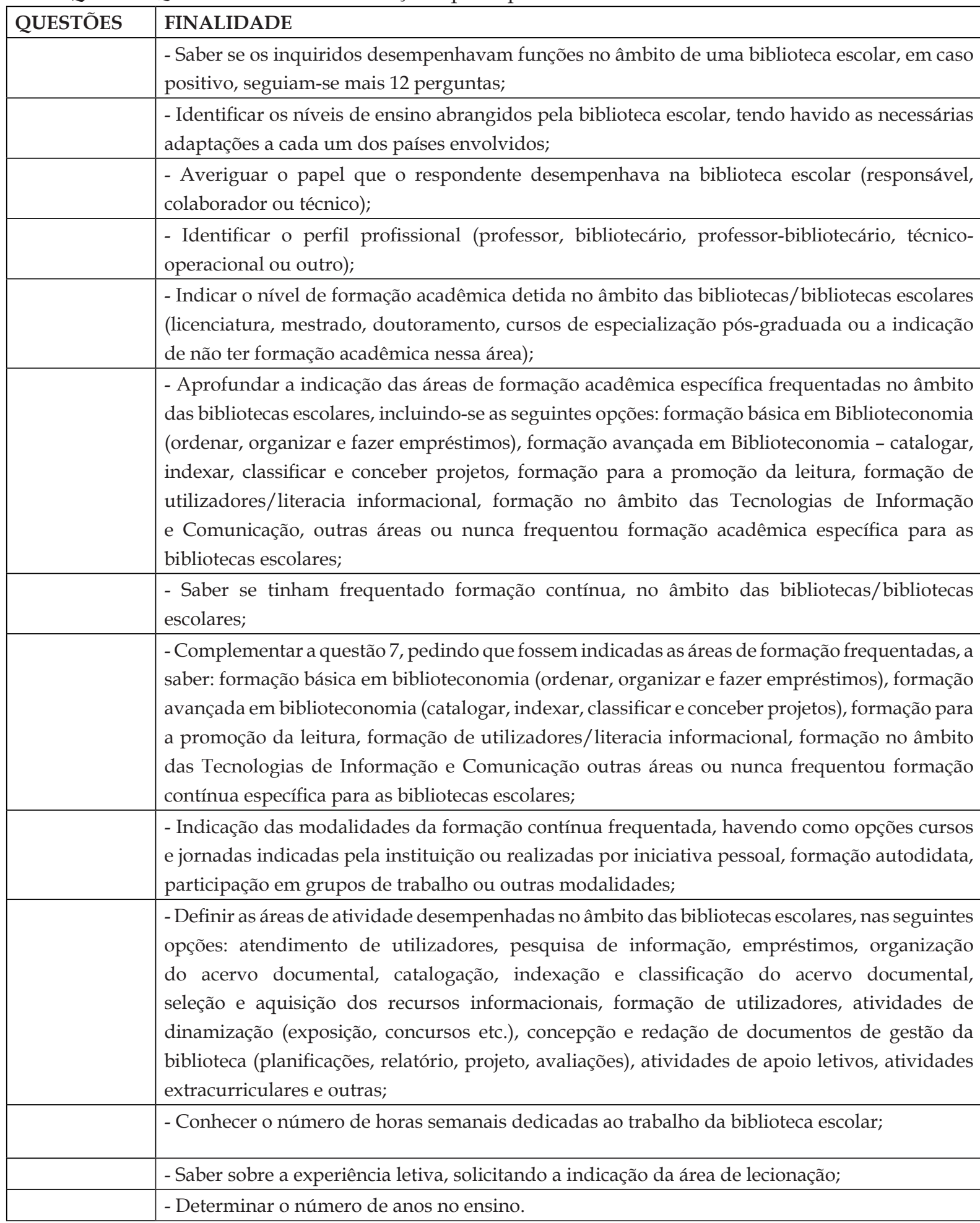

Fonte: Elaboração própria dos autores 